\title{
Radiological Manifestations of Obstructed Hemivagina and Ipsilateral Renal Anomaly Syndrome: A Rare Complex Müllerian and Wolffian Duct Anomaly
}

\author{
${ }^{1}$ Tushar L Patil, ${ }^{2}$ Devarati K Khurjekar, ${ }^{3}$ Vikash Y Ojha
}

\begin{abstract}
Obstructed hemivagina and ipsilateral renal anomaly (OHVIRA) syndrome is a rare complex Müllerian and Wolffian duct anomaly. It is also known as Herlyn-Werner-Wunderlich syndrome (HWWS). It includes unilateral renal anomalies and uterine didelphys. It generally occurs at puberty and exhibits non-specific and variable symptoms with acute or pelvic pain shortly following menarche, causing a delay in the diagnosis. We report here a 16 -year-old female presenting with progressive cyclical pelvic pain, where magnetic resonance imaging (MRI) suggested the diagnosis of the OHVIRA syndrome. She was managed by surgical resection of the septum and draining of the obstructed vagina.
\end{abstract}

Keywords: Herlyn-Werner-Wunderlich syndrome, Müllerian duct anomaly, OHVIRA syndrome, Renal agenesis, Uterus didelphys.

How to cite this article: Patil TL, Khurjekar DK, Ojha VY. Radiological Manifestations of Obstructed Hemivagina and Ipsilateral Renal Anomaly Syndrome: A Rare Complex Müllerian and Wolffian Duct Anomaly. Int J Recent Surg Med Sci 2016;2(1):33-39.

Source of support: Nil

Conflict of interest: None

\section{INTRODUCTION}

Obstructed hemivagina and ipsilateral renal anomaly (OHVIRA) syndrome is a rare congenital anomaly of Müllerian (paramesonephric) and Wolffian (mesonephric) ducts. It is also known as the Herlyn-Werner-Wunderlich syndrome (HWWS). Purslow ${ }^{1}$ first reported it as a combination of obstructed hemivagina and uterus didelphys. Classical OHVIRA syndrome with triad was reported in $1950 .^{2}$ Müllerian anomalies are present in 0.8 to $4 \%$ of the female population and the OHVIRA syndrome comprises about 0.1 to $3.5 \%$ of those Müllerian abnormalities. ${ }^{3}$ Diagnosis in most cases is late due to its rare incidence and non-specific clinical presentation, ${ }^{4-7}$ and also menstrual flow that comes from the patent unobstructed hemivagina gives the appearance of normal menses.

${ }^{1}$ Resident, ${ }^{2}$ Consultant Radiologist, ${ }^{3}$ Consultant Radiologist and Head

${ }^{1-3}$ Department of Radiology, Jehangir Hospital, Pune, Maharashtra India

Corresponding Author: Tushar L Patil, Resident, Department of Radiology, Jehangir Hospital, Pune, Maharashtra, India, Phone: +917709784155, e-mail: tusharpatil1407@gmail.com

\section{CASE REPORT}

A 16-year-old female presented with complaints of acute lower abdominal pain and mild dysmenorrhea. Her menarche had occurred at the age of 12 and she had regular menstruation, once every 30 days for 4 to 5 days. Physical examination revealed tenderness over the right lower quadrant of the abdomen. External genital inspection showed an intact hymen and menstrual discharge. She underwent ultrasonographic evaluation, which revealed two widely separated uterine horns and large heteroechoic cystic mass at the lower aspect of both uterine horns (Figs 1A and C). Right uterine horn was distended with heteroechoic fluid and was clearly connected to the cystic mass, consistent with hematometrocolpos (Figs 1B and D). Communication
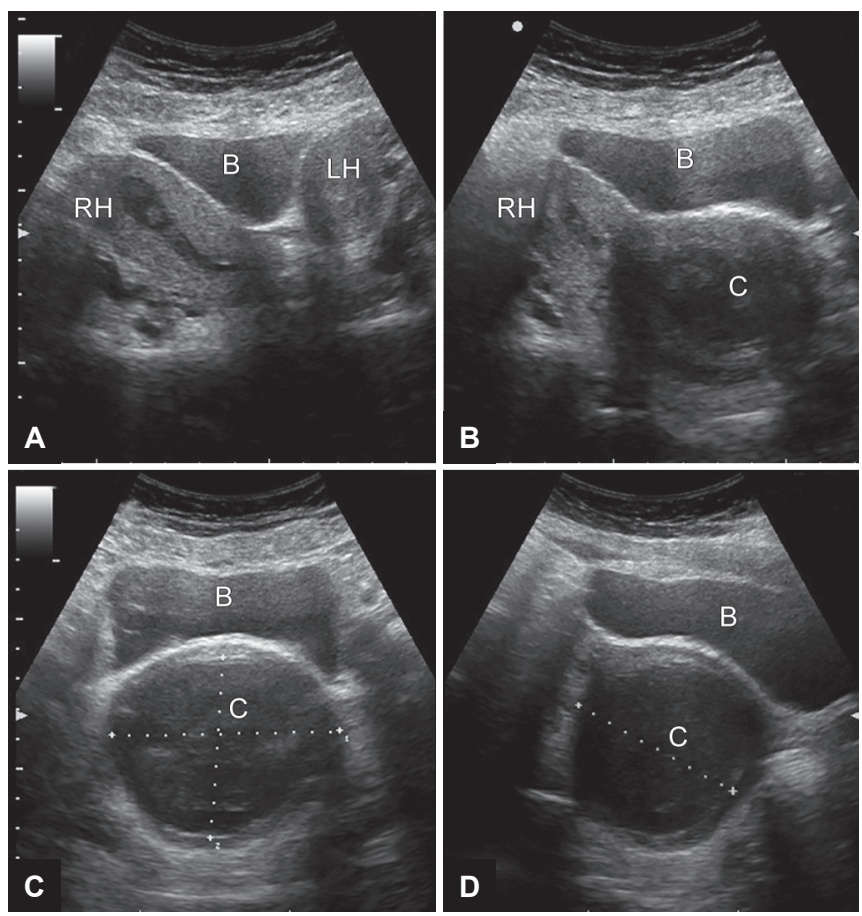

Figs 1A to C: (A) Axial transabdominal USG image showing right $(\mathrm{RH})$ and left (LH) uterine horns. Endometrial cavity of right horn is distended with heteroechoic fluid, suggestive of hematometra. No collection seen in left horn; (B) Oblique transabdominal USG image showing endometrial cavity of the right uterine horn $(\mathrm{RH})$ communicating with the heteroechoic lesion (C); and (C and D) Axial and sagittal USG images directed further caudally shows the heteroechoic lesion to be an ovoid fluid collection with internal echoes, located posterior to the urinary bladder (B). It appears to end slightly above the introitus, suggestive of hematocolpos 


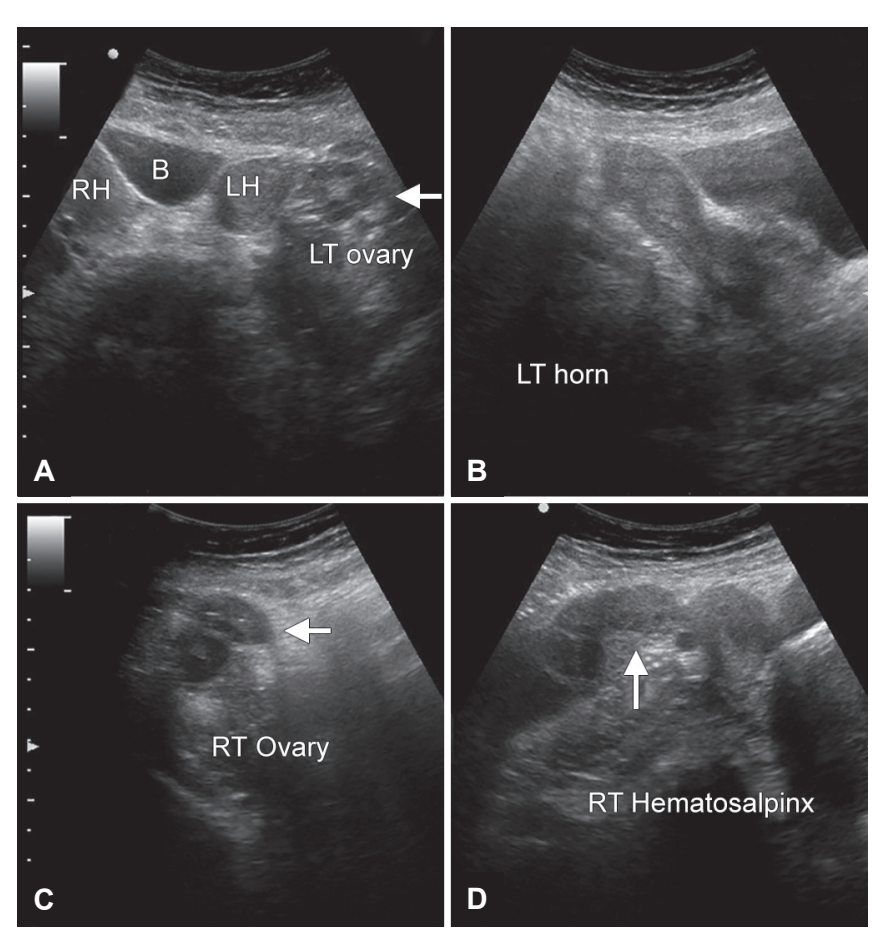

Figs 2A to D: (A) Axial transabdominal USG image showing right $(\mathrm{RH})$ and left (LH) uterine horns and normal left ovary; (B) Sagittal transabdominal USG image showing left uterine horn not communicating with the heteroechoic lesion, suggestive of the possibility of a bicornuate uterus or uterine didelphys; (C) Axial USG showing normal right ovary in close proximity to a heteroechoic tubular structure; and (D) A dilated tubular structure filled with slightly heteroechoic fluid and in close proximity to the right uterine horn, suggestive of hematosalpinx between the left uterine horn and hematocolpos was not clearly visualized (Figs 2A to C), which suggested the possibility of bicornuate uterus or uterine didelphys. A dilated tubular structure filled with slightly heteroechoic fluid and in close proximity to the right uterine horn was also observed, consistent with hematosalpinx (Fig. 2D). Right kidney was not visualized, and left kidney was relatively hypertrophied. Magnetic resonance imaging (MRI) was performed for further evaluation. Magnetic resonance imaging showed two completely separate uterine horns with normal zonal anatomy, two separate cervices, and large hematocolpos connected to the right uterine horn, corresponding to obstructed right hemivagina (Figs 3 to 5 ). Right-sided hematometra and hemotosalpinx (Figs 3) were also seen. Left uterine horn had its own opening into the left hemivagina (Figs 6 and 7). Both ovaries appeared normal, and right kidney was absent. Based on imaging findings of uterine didelphys, unilateral obstructed hemivagina with resultant hematometrocolpos and hematosalpinx, and unilateral renal agenesis, the case was diagnosed as OHVIRA syndrome.

Vaginal septotomy and drainage of $150 \mathrm{~mL}$ of hematometrocolpos and hematosalpinx were performed, and patient was discharged without any immediate complications. On follow-up, patient showed no complications and had normal menstrual flow.
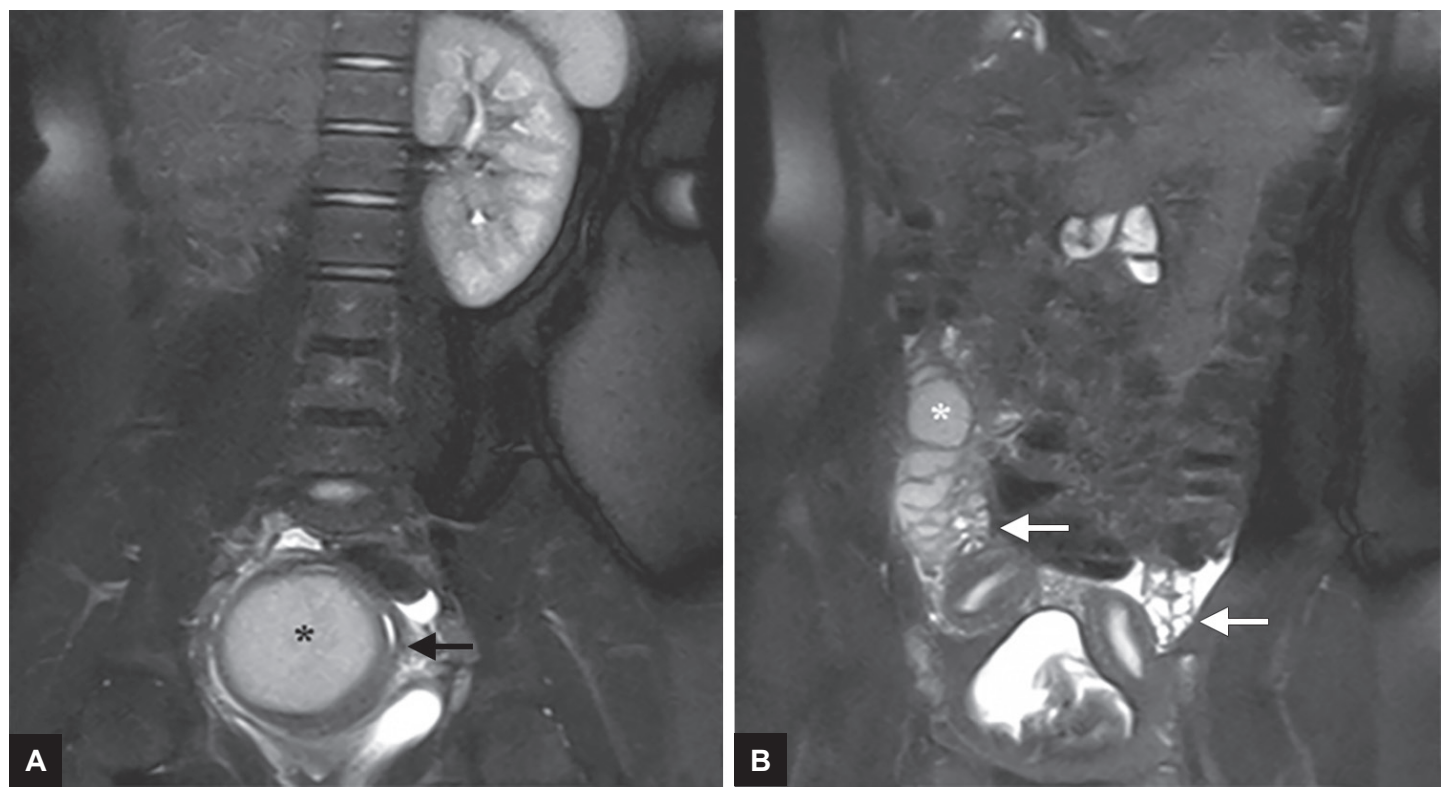

Figs 3A and B: (A) Coronal HASTE T2W image shows absence of the right kidney. The distended hemivagina (black asterisk) is seen on the right side and the normal collapsed left hemivagina with minimal fluid is seen adjacent to it (black arrow). The distended hemivagina ends above the introitus, and (B) Coronal HASTE T2W image shows right and left uterine horns, both ovaries (white arrows). A dilated tubular, slightly hyperintense structure is seen in close proximity to the right uterine horn, consistent with a hematosalpinx (white arrow) 

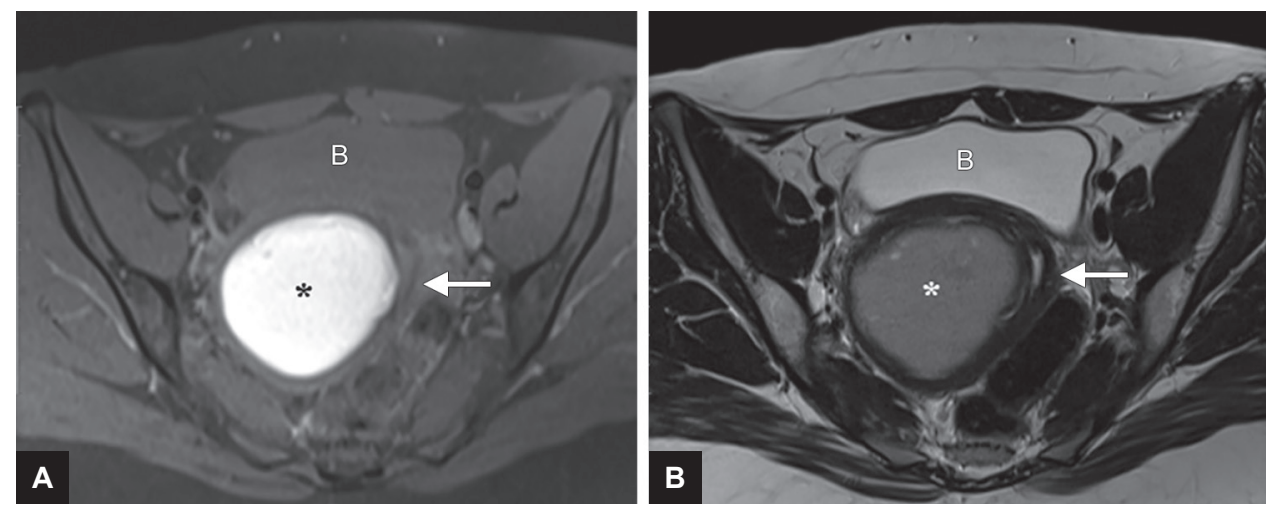

Figs 4A and B: (A)Axial fat saturated T1W image of the pelvis shows hyperintense signal of the right hemivaginal collection (asterisk). The collapsed hypointense left hemivagina is seen adjacent to it (arrow), and (B) Axial T2W image of the pelvis showing heterogenous hypointense right hemivaginal collection (asterisk) and collapsed hyperintense left hemivagina with minimal fluid (arrow)
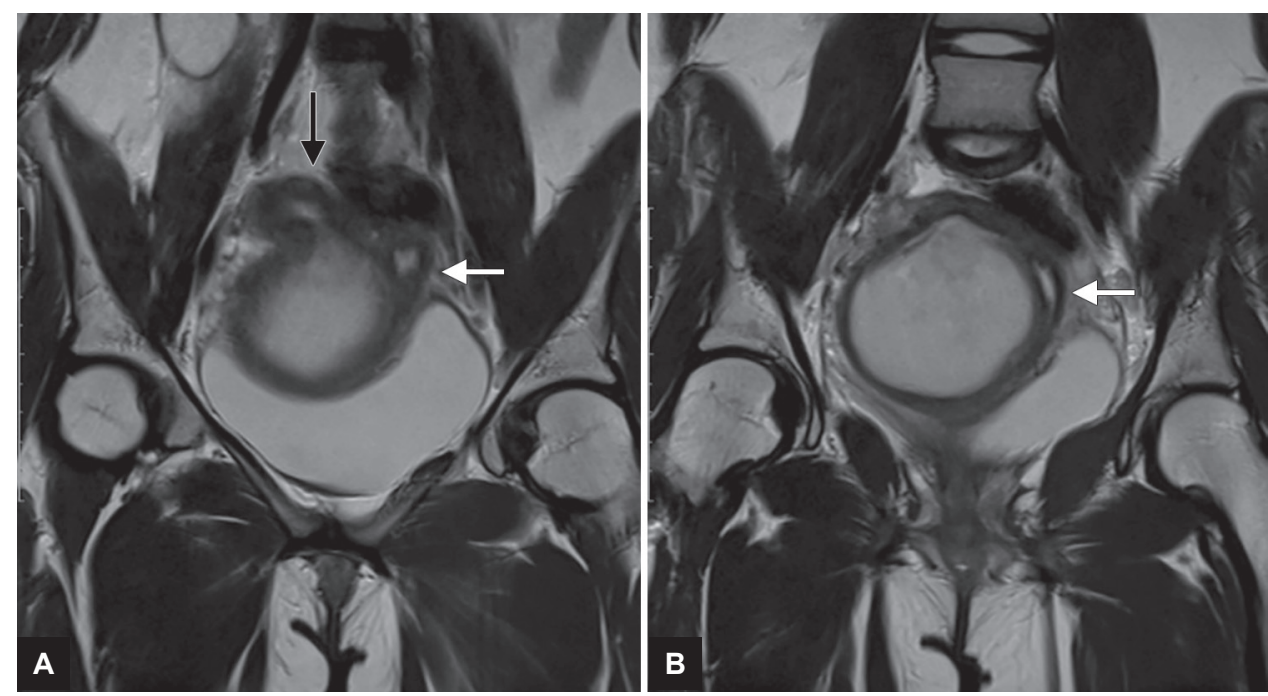

Figs 5A and B: (A) Coronal T2W image of the pelvis shows communication of hyperintense right hematometra with the right hematocolpos (black arrow). The collapsed hyperintense left hemivagina is seen adjacent to it (white arrow), and (B) Coronal T2W image of the pelvis showing heterogenous hyperintense right hematocolpos and collapsed hyperintense left hemivagina with minimal fluid (white arrow). No communication is visualized in these two images
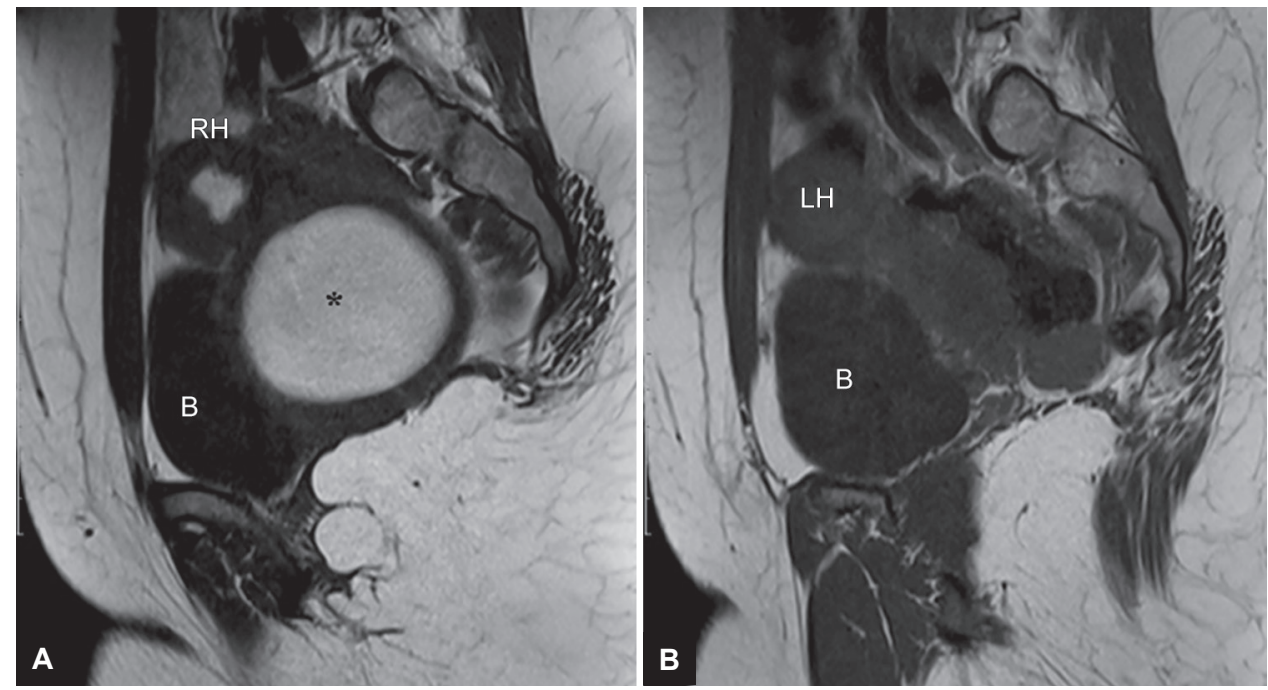

Figs 6A and B: (A) Sagittal T1W image of the pelvis shows hyperintense right hematometra $(\mathrm{RH})$ with the right hematocolpos (asterisk), and (B) Sagittal T1W image of the pelvis showing hypo to isointense left horn (LH) 


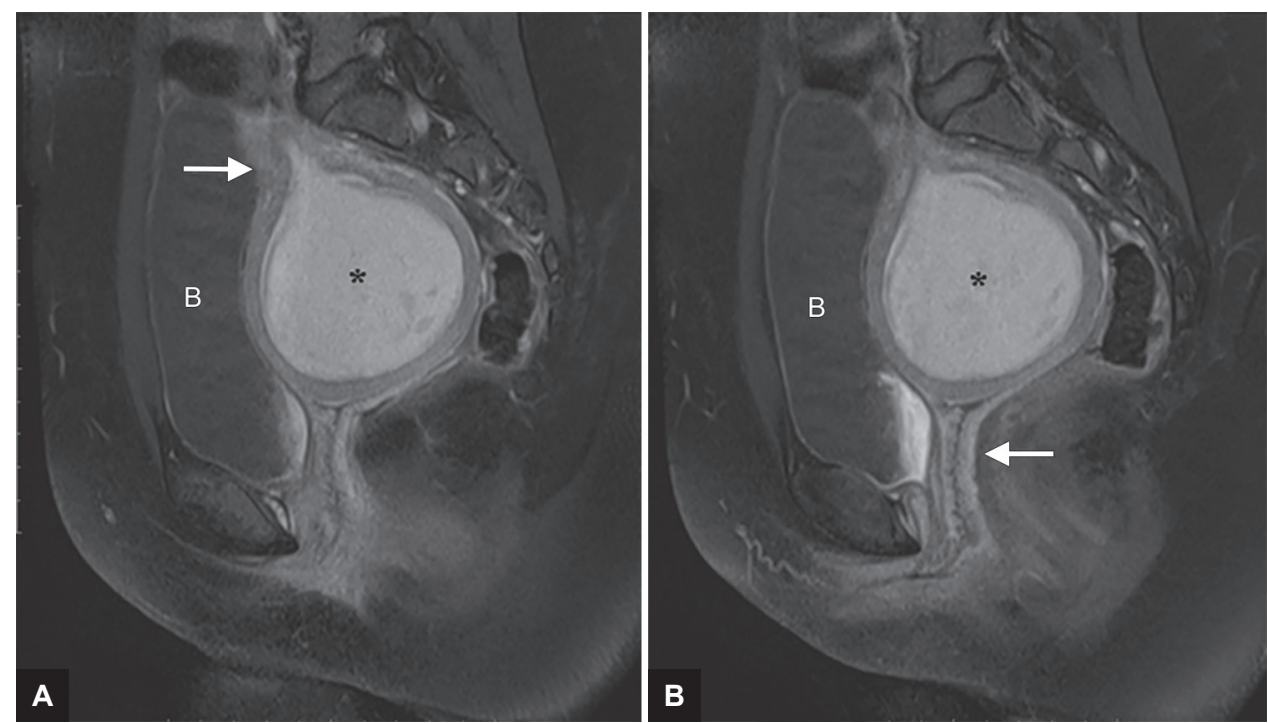

Figs 7A and B: (A) Sagittal post-contrast fat-saturated T1W image of the pelvis shows communication of hyperintense right hematometra with the right hematocolpos (white arrow). The collapsed left hemivagina is well seen adjacent to it due to mucosal enhancement (white arrow), and (B) Sagittal post-contrast fat-saturated T1W image of the pelvis shows completely separate left hemivagina from the hematocolpos. Due to mucosal enhancement, the vaginal cavity is well seen (white arrow)

\section{DISCUSSION}

Obstructed hemivagina and ipsilateral renal anomaly is rare Müllerian duct anomaly (MDA). Incidence of Müllerian defects is about 0.8 to $4 \% .^{1}$ In women with recurrent miscarriages and subfertility, it is much higher - around $25 \% .{ }^{8}$ Mean incidence of uterus didelphys was $11.1 \%^{8}$ with strong association of renal agenesis with uterus didelphys about $81 \%{ }^{9}$ Until 2011 , only about 200 documented cases were there in the world literature.

Herlyn-Werner-Wunderlich syndrome is characterized by uterus didelphys, obstructed hemivagina, and ipsilateral renal agenesis, i.e., combination of Type III MDA with mesonephric duct anomaly with vaginal septum. Obstructed hemivagina and ipsilateral renal anomaly syndrome is a broader term than HWWS, including other types of renal abnormalities, such as, renal agenesis, double collector, duplication renal system, horse-shoe kidney, duplicated kidneys, dysplastic kidneys, ${ }^{10}$ rectovesical bands, ${ }^{11}$ or crossed fused ectopia. ${ }^{12}$ Same sided renal anomalies as obstructed hemivagina are always seen, which is explained by embryology. Right side is affected twice as often as the left side. ${ }^{13}$ In the case of unicornuate uterus, renal anomalies are ipsilateral to rudimentary or absent uterine horn. ${ }^{14}$

There is no universally accepted MDA classification system. Each system has its limitations. Buttram and Gibbons proposed a system for classification of MDAs in 1979, which classifies them into six categories. American Society of Reproductive Medicine (ASRM) revised it in 1988 into seven categories. Now it is the most frequently used classification ${ }^{15}$ (Table 1). Limitation of these classification systems ${ }^{16}$ is their lack of categorization of vaginal
Table 1: American Society of Reproductive Medicine (ASRM) classification of Müllerian duct anomalies

\begin{tabular}{|c|c|c|}
\hline Class & Name & Description \\
\hline 1 & $\begin{array}{l}\text { Mayer- } \\
\text { Rokitansky- } \\
\text { Kuster-Hauser } \\
\text { syndrome or } \\
\text { Müllerian } \\
\text { agenesis }\end{array}$ & $\begin{array}{l}\text { Hypoplasia of the tubes, uterus, cervix, } \\
\text { or vagina }\end{array}$ \\
\hline II & $\begin{array}{l}\text { Unicornuate } \\
\text { uterus or } \\
\text { Unilateral } \\
\text { Müllerian } \\
\text { anomaly }(15 \%)\end{array}$ & $\begin{array}{l}\text { No rudimentary horn }(35 \%) \\
\text { Non-cavitatory rudimentary horn }(33 \%) \\
\text { Cavitatory rudimentary horn } \\
\text { [communicating }(10 \%) \text { or non- } \\
\text { communicating }(22 \%) \text { ] }\end{array}$ \\
\hline III & $\begin{array}{l}\text { Uterus } \\
\text { didelphys }\end{array}$ & $\begin{array}{l}\text { Two separate uterine horns and two } \\
\text { cervices }\end{array}$ \\
\hline IV & $\begin{array}{l}\text { Bicornuate } \\
\text { uterus }\end{array}$ & $\begin{array}{l}\text { Complete (septum extends to the } \\
\text { internal or external os) } \\
\text { Partial (septum is confined to the } \\
\text { fundal region) } \\
\text { Two separate uterine horns and single } \\
\text { cervix } \\
\text { Fundal depression separating the two } \\
\text { horns greater than } 1 \mathrm{~cm} \\
\text { Intercornual distance greater than } 4 \mathrm{~cm}\end{array}$ \\
\hline V & Septate uterus & $\begin{array}{l}\text { Complete (septum extends to the } \\
\text { internal os) } \\
\text { Partial (septum does not reach the } \\
\text { internal os) } \\
\text { Fundal depression separating the two } \\
\text { horns is less than } 1 \mathrm{~cm} \\
\text { Intercornual distance less than } 4 \mathrm{~cm}\end{array}$ \\
\hline VI & Arcuate uterus & $\begin{array}{l}\text { Normal variant } \\
\text { Endometrial cavity is not divided } \\
\text { External contour of uterus is flattened } \\
\text { or minimally concave }\end{array}$ \\
\hline VII & $\begin{array}{l}\text { T-shaped } \\
\text { uterus }\end{array}$ & $\begin{array}{l}\text { Results from in utero exposure to } \\
\text { diethylstilbestrol }\end{array}$ \\
\hline
\end{tabular}


Table 2: Embryological-clinical classification for female genitourinary malformations (revised and updated from Acién, 1992; and Acién et al., 2004a)

\begin{tabular}{lll}
\hline Group & Name & Description \\
\hline 1 & Unilateral genitourinary agenesis & 1.1 With contralateral Müllerian agenesis \\
& or hypoplasia & 1.2 Without contralateral agenesis \\
& Uterine duplicity with a blind & 2.1 Large hematocolpos, blind hemivagina \\
& hemivagina and ipsilateral & 2.2 Like Gartner's pseudocyst \\
& renal agenesis & 2.3 Partial reabsorption of the vaginal septum \\
& & 2.4 Complete unilateral vaginal or cervicovaginal atresia with communicating uteri \\
3 & Isolated or common uterine & A. Paramesonephric or Müllerian ducts including same 7 types as American Society of \\
& or utero-vaginal anomalies & Reproductive Medicine (ASRM) classification of Müllerian duct anomalies (Table 1) \\
& & B. Müllerian tubercle \\
& & B.1 Complete vaginal or cervicovaginal agenesis or atresia \\
& & B.2 Segmentary atresias \\
4 & Accesory uterine masses and other & Accesory and cavitated uterine masses with normal uterus \\
& gubernaculum dysfunctions & \\
& Anomalies of the urogenital sinus & Imperforated hymen \\
& & Persistent urogenital sinus \\
& & Congenital vesicovaginal fistula \\
& Malformative combinations & Variable \\
\hline
\end{tabular}

and other anomalies that bridge more than one classification. ${ }^{17,18}$ Acién et $\mathrm{al}^{19}$ in 2011 and Singh et $\mathrm{al}^{20}$ in 1993 proposed an updated embryological-clinical classification of genitourinary malformations, which integrates current embryological and pathogenic concepts and is clinically applicable and useful (Table 2).

Review of embryology of uterovaginal development is important to understand pathogenesis of MDAs and their association with renal anomalies. Classic theory of vaginal development was given by Koff. ${ }^{21}$ It was found inadequate in explaining complex MDA, such as, OHVIRA and their coexistence with renal anomalies. Pathogenesis of majority of these complex anomalies can be correctly explained and understood through embryological hypothesis for female genital tract presented by Acién ${ }^{22}$ and revised by Acién et $\mathrm{al}^{23}$ Sánchez-Ferrer et $\mathrm{al}^{24}$ and Acién and Acién. ${ }^{25}$ Acién proposed that vagina has complete mesonephric (Wolffian) origin although its lining did reveal Müllerian cells derived from Müllerian tubercle, while uterus and cervix were derived from fused paired paramesonephric ducts. Thus, formation of vagina does not include paramesonephric ducts although Müllerian tubercle does explain vaginal lining. This has been proved to an extent by data published by SánchezFerrer et $\mathrm{al}^{24}$ in his experiments with female rats using histoimmunochemistry techniques.

Embryopathogenesis of HWWS can be temporally located around 8 weeks of gestation. ${ }^{20}$ Agenesis of ureteric bud results due to early failure of development of metanephric diverticulum from mesonephric duct (around 5 weeks). This leads to agenesis of ipsilateral ureter and kidney. Development and positioning of paired paramesonephric duct in close proximity is done by mesonephros. At around 9 weeks gestation, paramesonephric duct is positioned in such a manner that it is lateral to the mesonephric duct in the first part, crosses it anteriorly, and lies medial to it in the converging portion. If the Wolffian duct is absent, the Müllerian duct moves laterally (in space where the Wolffian duct is absent) and may not be merged with the contralateral duct, giving a uterus didelphys. Failure of development of distal hemivagina due to developmental arrest of ipsilateral mesonephric duct results in obstructed hemivagina. This occurs in OHVIRA syndrome. Introitus is not compromised, because its embryological origin comes from urogenital sinus. Mesonephric remnant can stay in the vaginal wall and sometimes become Gartner's cyst. All 3 components of OHVIRA syndrome, i.e., uterus didelphys, unilateral low vaginal obstruction, and ipsilateral renal agenesis, are secondary to mesonephric ductinduced MDA.

Obstructed hemivagina and ipsilateral renal anomaly syndrome is generally detected in newborns or shortly after menarche usually based on suspicion. It is detected in neonates if fetal ultrasonography (USG) showed unilateral renal agenesis or multicystic dysplastic kidney. It is recommended to seek Müllerian duct obstruction and look for genital abnormalities. Uterine anomalies are best detected in the neonatal period where uterus is still under maternal hormonal stimulation (prominent echogenic endometrium and myometrium on USG) and worse in childhood to menarche, where the uterus size and shape do not allow diagnosis. In adolescents, it may be suspected clinically but usually detected on imaging while presenting with non-specific complaints. Patients usually present with pelvic pain or dysmenorrhea, with 
or without palpable mass due to hematocolpos or hematometra. ${ }^{26}$ Accurate and early diagnosis is essential, as incidence of complications including endometriosis, menstrual disorders, infertility, and obstetric complications increases with time. ${ }^{13,26}$ Endometriosis is a frequent complication because of the obstructed outflow of part of menstrual blood that collects in obstructed Müllerian derivatives, leading to hematometra, hematosalpinx, and peritoneal endometriosis, confirming the theory postulated by Sampson. ${ }^{27}$

Ultrasound and MRI are most commonly used imaging modalities in diagnosis of MDA. Hysterosalpingography (HSG) is typically indicated in initial stages of infertility work-up. Ultrasonography is frequently used as initial investigation and preferred as it is non-invasive, free of radiation, and widely available but cannot identify types of MDA. ${ }^{28-30}$ Magnetic resonance imaging is ideal imaging modality for noninvasive evaluation of female pelvic anatomy because it provides more detailed information regarding uterine morphology, continuity with each vaginal lumen, character of vaginal septum, and nature of fluid contents. It is more useful in detection of associated conditions, such as, endometriosis, pelvic inflammation and adhesions, and coexisting urologic anomalies. ${ }^{31}$ Laparoscopy is gold standard diagnostic modality with additional advantages of therapeutic drainage of hematocolpos/hematometra, vaginal septectomy, and marsupialization. ${ }^{32,33}$ However, it should be reserved when diagnosis is not clear after imaging or when MRI is not available and should not be performed as a routine procedure. Decision to perform laparoscopy is based on interval between menarche and diagnosis, severity of symptoms, and presence of hematometra or pyometra.

Resection of the obstructed vaginal septum to relieve obstruction is treatment of choice for symptom relief and preservation of reproductive capability, ${ }^{34}$ also reducing chances of pelvic endometriosis due to retrograde menstrual seeding. If surgery is to be delayed due to some circumstances, menstrual suppression with combined oral contraceptive pills is advised to prevent further accumulation of hematocolpos and further hematometra. ${ }^{35}$ Integrity of hymen represents major cultural issue in some communities. Hysteroscopic excision of vaginal septum in uterus didelphys is recommended for management of those patients with good outcome. ${ }^{36}$ Reconstruction of vagina can be accomplished by careful excision of the vaginal septum. Patients are able to have a normal sexual life. Altchek and Paciuc have reported pregnancy occurring twice in a previously obstructed didelphys uterus after surgical correction. ${ }^{37}$ Successful pregnancy is achieved eventually in $87 \%$ patients, while $23 \%$ have risk of abortions. ${ }^{38}$ Hence, the surgeon must make every effort to preserve the obstructed uterus. Hemihysterectomy done earlier is now no more preferred as the reported incidence of pregnancy in both horns is almost equal. Hemihysterectomy is only used in selected cases for which resection of the vaginal septum is not enough to relieve hematometrocolpos or recurrent vaginal stenosis develops. ${ }^{39}$

In conclusion, OHVIRA is a rare congenital complex Müllerian and Wolffian duct anomaly with simple singlestage surgical management, and MRI plays a major role in its diagnosis.

\section{REFERENCES}

1. Purslow CE. A case of unilateral haematocolpos, hematometra and haematosalpinx. J Obstet Gynaecol Br Emp 1922;29:643.

2. Embrey MP. A case of uterus didelphys with unilateral gynatresia. Br Med J 1950 Apr;1(4657):820e1.

3. Resetkova N, Christianson M, Kolp L. Uterine didelphys with obstructed hemivagina and ipsilateral renal agenesis with hydronephrosis. Fertil Steril 2012;97:s30-s31.

4. Shih CL, Hung YC, Chen CP, Chien SC, Lin WC. Resectoscopic excision of the vaginal septum in a virgin with uterus didelphys and obstructed unilateral vagina. Taiwan J Obstet Gynecol 2010 Mar;49(1):109-111.

5. Nigam A, Raghunandan C, Yadav R, Tomer S, Anand R. OHVIRA syndrome: rare cause of chronic vaginal discharge in an unmarried female. Congenit Anom 2011 Sep;51(3):153-155.

6. Mandava A, Prabhakar RR, Smitha S. OHVIRA syndrome (obstructed hemivagina and ipsilateral renal anomaly) with uterus didelphys, an unusual presentation. J Pediatr Adolesc Gynecol 2012 Apr;25(2):e23-e25.

7. Shavell VI, Montgomery SE, Johnson SC, Diamond MP, Berman JM. Complete septate uterus, obstructed hemivagina, and ipsilateral renal anomaly: pregnancy course complicated by a rare urogenital anomaly. Arch Gynecol Obstet 2009 Sep;280(3):449-452.

8. Acien P. Incidence of Müllerian defects in fertile and infertile women. Hum Reprod 1997 Jul;12(7):1372-1376.

9. Li S, Qayyum A, Coakley FV, Hricak H. Association of renal agenesis and mullerian duct anomalies. J Comput Assist Tomogr 2000 Nov-Dec;24(6):829-834.

10. Prada Arias M, Muguerza Vellibre R, Montero Sánchez M, Vázquez Castelo JL, Arias González M, Rodríguez Costa A. Uterus didelphys with obstructed hemivagina and multicystic dysplastic kidney. Eur J Pediatr Surg 2005 Dec;15(6):441-445.

11. Heinonen PK. Clinical implications of the didelphic uterus: long-term follow-up of 49 cases. Eur J Obstet Gynecol Reprod Biol 2000 Aug;91(2):183-190.

12. Tanaka YO, Kurosaki Y, Kobayashi T, Eguchi N, Mori K, Satoh Y, Nishida M, Kubo T, Itai Y. Uterus didelphys associated with obstructed hemivagina and ipsilateral renal agenesis: MR findings in seven cases. Abdom Imaging 1998 Jul-Aug;23(4):437-441.

13. Orazi C, Lucchetti MC, Schingo PM, Marchetti P, Ferro F. Herlyn-Werner-Wunderlich syndrome: uterus didelphys, blind hemivagina and ipsilateral renal agenesis. Sonographic and MR findings in 11 cases. Pediatr Radiol 2007 Jul;37(7): 657-665.

14. Brody JM, Koelliker SL, Frishman GN. Unicornuate uterus: imaging appearance, associated anomalies, and clinical implications. AJR Am J Roentgenol 1998 Nov;171(5):1341-1347. 
15. The American Fertility Society classifications of adnexal adhesions, distal tubal occlusion, tubal occlusion secondary to tubal ligation, tubal pregnancies, müllerian anomalies and intrauterine adhesions. Fertil Steril 1988 Jun;49(6):944-955.

16. Buttram VC, Gibbons WE. Müllerian anomalies: a proposed classification. (An analysis of 144 cases.) Fertil Steril 1979 Jul;32(1):40-46.

17. Troiano RN, McCarthy SM. Mullerian duct anomalies: imaging and clinical issues. Radiology 2004 Oct;233(1):19-34.

18. Olpin JD, Heilbrun M. Imaging of müllerian duct anomalies. Clin Obstet Gynecol 2009 Mar;52(1):40-56.

19. Acién $P$, Acién MI. The history of female genital tract malformation classifications and proposal of an updated system. Hum Reprod Update 2011 Sep-Oct;17(5):693-705.

20. Singh M, Geareart JP, Rock JA. Double urethra, double bladder, left renal agenesis, persistent hymen, double vagina and uterus didelphys. Adolesc Pediatr Gynecol 1993;6:99.

21. Koff AK. Development of the vagina in the human fetus. Contrib Embryol 1933 Sep;24(140):59-91.

22. Acién P. Embryological observations on the female genital tract. Hum Reprod 1992 Apr;7(4):437-445.

23. Acién P, Acién M, Sánchez-Ferrer ML. Complex malformations of the female genital tract. New types and revision of classification. Hum Reprod 2004 Oct;19(10):2377-2384.

24. Sánchez-Ferrer ML, Acién MI, Sánchez del Campo F, Mayol-Belda MJ, Acién P. Experimental contributions to the study of the embryology of the vagina. Hum Reprod 2006 Jun;21(6):1623-1628.

25. Acién P, Acién MI. Malformations of the female genital tract and embryological bases. Curr Women's Health Rev 2007;3:248-288.

26. Lopes Dias J, Jogo R. Herlyn-Werner-Wunderlich syndrome: pre- and post-surgical MRI and US findings. Abdom Imaging 2015 Oct;40(7):2667-2682.

27. Brosens IA, Brosens JJ. Endometriosis. Eur J Obstet Gynecol Reprod Biol 2000 Jun;90(2):159-164.

28. Del Vescovo R, Battisti S, Di Paola V, Piccolo CL, Cazzato RL, Sansoni I, Grasso RF, Zobel BB. Herlyn-Werner-Wunderlich syndrome: MRI findings, radiological guide (two cases and literature review), and differential diagnosis. BMC Med Imaging 2012 Mar;12:4.
29. Behr SC, Courtier JL, Qayyum A. Imaging of mullerian duct anomalies. Radiographics 2012 Oct;32(6):E233-250.

30. Han B, Herndon CN, Rosen MP, Wang ZJ, Daldrup-Link H. Uterine didelphys associated with obstructed hemivagina and ipsilateral renal anomaly (OHVIRA) syndrome. Radiol Case Reports 2010;5:327.

31. La Fianza A, Preda L, Di Maggio EM, Campani R. Blind megaureter with ipsilateral renal agenesis and mullerian anomaly: MR findings in a case. Clin Imaging 1999 May-Jun; 23(3):184-186.

32. Gholoum S, Puligandla PS, Hui T, Su W, Quiros E, Laberge JM. Management and outcome of patients with combined vaginal septum, bifid uterus and ipsilateral renal agenesis (Herlin-Werner-Wunderlich syndrome). J Pediatr Surg 2006 May;41(5):987-992.

33. Park NH, Park HJ, Park CS, Park SI. Herlyn-Werner-Wunderlich Syndrome with unilateral hemivaginal obstruction, ipsilateral renal agenesis and contralateral renal thin GBM disease: a case report with radiological follow up. J Korean Soc Radiol 2010;62:383-388.

34. Smith NA, Laufer MR. Obstructed hemivagina and ipsilateral renal anomaly (OHVIRA) syndrome: management and follow-up. Fertil Steril 2007 Apr;87(4):918-922.

35. Haddad B, Barranger E, Paniel BJ. Blind hemivagina: longterm follow-up and reproductive performance in 42 cases. Hum Reprod 1999 Aug;14(8):1962-1964.

36. Alborzi S, Tavana Z, Amini M. Hysteroscopic resection of vaginal septum in Didylphis uterus with hemiobstructed vagina. J Minim Invasive Surg Sci 2014;3:e13573.

37. Altchek A, Paciuc J. Successful pregnancy following surgery in the obstructed uterus in a uterus didelphys with unilateral distal vaginal agenesis and ipsilateral renal agenesis: case report and literature review. J Pediatr Adolesc Gynecol 2009 Oct;22(5):e159-e162.

38. Candiani GB, Fedele L, Candiani M. Double uterus, blind hemivagina, and ipsilateral renal agenesis: 36 cases and long term follow-up. Obstet Gynecol 1997 Jul;90(1):26-32.

39. Donnez O, Jadoul P, Squifflet J, Donnez J. Didelphic uterus and obstructed hemivagina: recurrent hematometra in spite of appropriate classic surgical treatment. Gynecol Obstet Invest 2007;63(2):98-101. 